\title{
Determination of glutamate pyruvate transaminase activity in clinical specimens using a biosensor composed of immobilized L-glutamate oxidase in a photo-crosslinkable polymer membrane on a palladium-deposited screen-printed carbon electrode
}

\author{
Ku-Shang Chang ${ }^{\mathrm{a}, \mathrm{b}}$, Wen-Lin Hsu ${ }^{\mathrm{c}}$, Hour-Young Chen ${ }^{\mathrm{d}}$, \\ Chen-Kai Chang ${ }^{a}$, Chien-Yuan Chen ${ }^{\mathrm{a}, *}$ \\ ${ }^{a}$ Graduate Institute of Agricultural Chemistry, National Taiwan University, No. 1, Sec. 4, Roosevelt Road, Taipei 106, Taiwan \\ ${ }^{\mathrm{b}}$ Department of Food Science, Yuanpei Technical College, Hsinchu, Taiwan \\ ${ }^{c}$ Cancer Medical Center, Buddhist Tzu Chi Medical Center, Hualein, Taiwan \\ d Department of Health, Center for Disease Control, The Executive Yuan of Taiwan, Taipei, Taiwan
}

Received 13 March 2002; received in revised form 14 January 2003; accepted 21 January 2003

\begin{abstract}
The determination of glutamate pyruvate activity (GPT) is of particular clinical importance. A portable GPT sensor for both diagnostic and home-care purpose is highly expected. A highly sensitive and stable L-glutamate sensor was fabricated for the rapid detection of the GPT activity in serum. The sensor is composed of immobilized L-glutamate oxidase in a photo-crosslinkable polymer (PVA-SbQ) membrane on a palladium-deposited screen-printed carbon electrode. The sensor exhibited high sensitivity (detection limit of $50 \mathrm{nM}$ for monosodium glutamate), remarkable long-term stability in storage ( 5 months in the dry dark state and 1 month in buffer solution) and good reproducibility (R.S.D. $=2.6 \%, n=100$ ). The electrode-to-electrode reproducibility was found to depend on the composition of the polymeric matrix. The optimal substrate composition for the detection of GPT activity was $1 \mathrm{mM} \alpha$-ketoglutarate and $100 \mathrm{mM} \mathrm{L}$-alanine. The GPT activity in serum can be determined within $3 \mathrm{~min}$. The response of the sensor to GPT activity is linear over the range of 8-250 U/l. Good correlation between the sensor and the Sigma GPT assay kit was achieved $\left(R^{2}=0.9958\right)$. The sensor is potentially applicable to a home-care purpose when a portable measuring device is adapted.
\end{abstract}

() 2003 Elsevier Science B.V. All rights reserved.

Keywords: GPT sensor; L-Glutamate oxidase; Photo-crosslinkable polymer; PVA-SbQ; Palladium-deposited screen-printed carbon electrode

\section{Introduction}

The determination of glutamate pyruvate activity (GPT) is of particular clinical importance. Elevated GPT value in serum indicates myocardial and hepatic

\footnotetext{
* Corresponding author. Tel.: +886-2-23630231x3256; fax: +886-2-23661696.

E-mail address: chenyuan@ccms.ntu.edu.tw (C.-Y. Chen).
}

diseases [1]. Many spectrophotometric and fluorimetric methods have developed for the assay of GPT activity [2-6]. All of these methods are based on the measurement of decreased absorbance of NADH, which is the coenzyme involved in the following reaction [7].

L-alanine $+\alpha$-ketoglutarate $\stackrel{\text { GPT }}{\rightarrow}$ pyruvate + L-glutamate 
pyruvate $+\mathrm{NADH}+\mathrm{H}^{+} \stackrel{\mathrm{LDH}}{\rightarrow}$ lactate $+\mathrm{NAD}^{+}$

In these methods, however, extra instrumentation is required and thus not suitable for point-of-care applications or home-use test systems. Furthermore, they 'do not give reliable results when sera are icteric or lipemic, or contain products of hemolysis that are common in clinical samples [8].

Recent trends in research and development have put increased emphasis on the manufacture of portable biosensing systems [9-11]. Electrochemical biosensors composed of an enzyme-modified screen-printed carbon strip have been developed and commercialized [12]. The electroactive species generated during the enzymatic reaction are measured amperometrically by these sensors. Colorful and turbid medias make no interference to the measurement [8].

Biosensors for the measurement of GPT in serum have been developed by immobilization of L-glutamate oxidase on an electrode [13-16]. The L-glutamate generated from the transamination of $\alpha$-ketoglutarate is converted to hydrogen peroxide and $\alpha$-ketoglutarate by L-glutamate oxidase (L-GLOx, EC 1.4.3.7). Hydrogen peroxide is an electroactive species, which is easily oxidized, to induce a current flow. The rate of current increase is proportional to the concentration of GPT in the sample as shown in the following equations.

$$
\begin{aligned}
& \stackrel{\text { L-glutamate }+\mathrm{O}_{2}}{\stackrel{\text { L-GLOx }}{\rightarrow}} \alpha \text {-ketoglutarate }+\mathrm{NH}_{3}+\mathrm{H}_{2} \mathrm{O}_{2} \\
& \stackrel{\mathrm{H}_{2} \mathrm{O}_{2}}{\rightarrow} 2 \mathrm{H}^{+}+\mathrm{O}_{2}+2 \mathrm{e}^{-}
\end{aligned}
$$

The GPT activity is as low as $30 \mathrm{U} / \mathrm{l}$ in human serum [13]. The determination of GPT activity on L-glutamate-sensing electrodes has been reported to require as long as $10 \mathrm{~min}$ [14-16]. For achieving a rapid and highly sensitive measurement of the substrate, the following approach may be adopted. First, enzyme must be immobilized onto the electrode with high surface density. Second, the substrate must diffuse quickly through the thin-layer to undergo the enzymatic reaction. Third, the hydrogen peroxide liberated from enzymatic reactions in the vicinity of the electrode surface must be oxidized immediately.

Electrodes with thin enzyme-containing layers facilitate quick reaction of the substrate and enzyme better than those fabricated by using thick layers [13]. Recently, a thin-layer electrode consisting of a polyion complex layer membrane was fabricated to detect the GPT activity in sera rapidly [13]. However, a part of the polyion complex layer often became disloadged from the surface during the enzyme immobilization procedure and the layer tended to become damaged during the repetition of wetting and drying. Self-assembly technique has also been used for the fabrication of a thin-layer enzyme electrode [17]. However, the sensitivities of these enzyme electrodes in a self-assembled monolayer configuration are low due to the limited amounts of enzyme attached to the electrode surfaces [18]. A photo-crosslinkable polymer PVA-SbQ has also been reported to be suitable for fabrication of a thin enzyme membrane (about $1 \mu \mathrm{m}$ thick) [19]. Enzyme can be immobilized in the matrix with high surface density and retain their functional characteristics to a large extent for several months upon repetition of wetting and drying [20]. Moreover, enzymes can be immobilized in this polymer using photolithography techniques [21,22], which can be adapted to mass production using ordinary screen-printing or semiconductor-fabrication processes on a planar electrode [19,23].

A large electrode surface area is required for the rapid and effective detection of hydrogen peroxide as shown by a rapid and large current response. Some substances such as platinum, rhodium and palladium can be deposited onto the electrode surfaces prior to the immobilization of enzyme. The deposition of particles of these elements on the electrode surface produces a very porous structure consisting of aggregates of fine metal particles. This results in an increase in the electrode surface area, an increase in surface activity that can be used for the detection of the hydrogen peroxide liberated from enzymatic reactions [24-27].

However, such electrodes with a thin-layer enzyme membrane or with a large surface area electrode often suffer from electrochemical interference by oxidizable species (e.g. L-ascorbic acid, uric acid, and acetaminophen) [13]. These interferants, as well as hydrogen peroxide, are oxidized on the electrode to give a large current response. The increase in the background current causes difficulty in accurately measuring the rate of current increase with the enzymatic L-glutamate production [28]. To avoid the interference from oxidizable species, depositing suitable 
electrocatalytic metal on the electrode to decrease the overpotential of the reduction of hydrogen peroxide [29-32] is useful. Palladium is often chosen to modify the electrode because it is one of the most difficult noble metals to oxidize, it has a powerful electrocatalytic activity and it is relatively inexpensive. These qualities not only increase the surface area but also dramatically decrease the overpotential of the reduction of hydrogen peroxide and improve its electrochemical response [26]. Furthermore, as aggregates of palladium particles form many open "micropockets", the enzyme film can be strongly adsorbed into the three-dimensional matrix [29], contributing to the shelf life of the enzyme electrode.

In this study, a screen-printing carbon strip deposited with palladium was used as the electrode. Then a PVA-SbQ containing L-GLOx (EC 1.4.3.7) layer was formed on the electrode to fabricate an L-glutamate sensor. In order to improve the sensitivity and reproducibility of the sensor, the optimum composition of the immobilized layer was studied. The sensor was used to detect the GPT activity in sera. The optimum operation conditions and the reproducibility of the sensor were also studied.

\section{Experimental}

\subsection{Materials}

Bovine serum albumin (BSA), monosodium glutamate (MSG), L-alanine, glutaraldehyde, $\alpha$-ketoglutarate $(\alpha-\mathrm{KG})$, palladium chloride (Pd) and GPT (EC 2.6.1.2, from porcine heart) were purchased from Sigma, and PVA-SbQ solution with $10 \mathrm{wt}$ \% concentration was from Tokyo Chemical (Tokyo, Japan). The enzyme L-GLOx (EC 1.4.3.11) was produced in this laboratory from Streptomyces sp. NTU 3304. The screen-printing carbon strip (SPCS) was obtained from ApexBichem (Hsinchu, Taiwan). All other reagents were of analytical grade.

\subsection{Electrodeposition of palladium}

An SPCS $\left(4.8 \mathrm{~mm}^{2}\right)$ was immersed in a solution containing $5 \mathrm{mM}$ palladium chloride, The strip was electrodeposited by cyclic potential scanning between -0.4 and $1.0 \mathrm{~V}$ versus $\mathrm{Ag} / \mathrm{AgCl}$ at $50 \mathrm{mV} / \mathrm{s}$ for $10 \mathrm{~min}$, then the strip was washed with distilled water and dried in air.

\subsection{Enzyme immobilization}

The palladium-modified enzyme electrodes $(\mathrm{Pd} /$ PVA-SbQ/L-GLOx) were prepared as follows: The enzymes were immobilized by a combination of PVA-SbQ photo-crosslinking and glutaraldehyde exposure. A mixture of $50 \mathrm{mg}$ of PVA-SbQ solution, $10 \mathrm{mg} \mathrm{BSA}$ and $140 \mathrm{mg}$ L-GLOx solution $(100 \mathrm{U} / \mathrm{ml})$ was prepared and $1 \mu l$ of this mixture was doped onto the active area of the electrode. The sensor was then placed in a dark sealed box containing glutaraldehyde vapor. The box was kept at $4{ }^{\circ} \mathrm{C}$ for $12 \mathrm{~h}$ to complete crosslinking, then the sensor was exposed to UV light for $25 \mathrm{~min}$.

\subsection{Apparatus and procedure}

Voltammetric and amperometric measurements were performed using a laboratory-built potentiostat. Input and output signals from the potentiostat were coupled to a PC (Pentium $166 \mathrm{MHz}$ ) using a peripheral interface card (AT-MIO-16E, National Instruments, Austin, Texas, USA). The interface card consisted of a 16-channel analog-to-digital (A/D) converter (12 bit) and a 2-channel digital-to-analog (D/A) converter (12 bit). Voltage output, data display and recording were programmed using the LabVIEW 5.1 software package (National Instruments, Austin, Texas, USA). All measurements were taken with a three-electrode system using an $\mathrm{Ag} / \mathrm{AgCl}$ electrode as a reference and an palladium-modified SPCS $\left(4.8 \mathrm{~mm}^{2}\right)$ as the working electrode. The cyclic voltametric experiments were performed in an unstirred $100 \mathrm{mM}$ phosphate buffer (100 mM, pH 7.0) solution. The scan rate of the potential was $50 \mathrm{mV} / \mathrm{s}$. The amperometric measurement was performed at $400 \mathrm{mV}$ versus $\mathrm{Ag} / \mathrm{AgCl}$. The working solution was $9.9 \mathrm{ml}$ PBS buffer ( $\mathrm{pH} 7.0$ ) in a cylindrical cell, with temperature controlled using a thermostat. Unless otherwise stated, all experiments were carried out at $35^{\circ} \mathrm{C}$. For the amperometric measurement of MSG, $0.1 \mathrm{ml}$ of MSG solution was injected into the test solution using a microsyringe when a steady state of the testing-system had been obtained. The baseline current was measured, and then, following the injection of MSG, the response current was 
displayed and simultaneously logged by the computer until a steady state was achieved. Magnetic stirring during the operation was used to ensure the homogeneity of the solution. The difference between the baseline and the steady-state current was used to calculate the concentration of MSG. Calibration curves to determine sensor sensitivity were obtained by measuring the MSG concentration from 0.05 to $100 \mu \mathrm{M}$. All of the solutions used in the GPT activity measurements were prepared with $100 \mathrm{mM}$ sodium phosphate buffer (pH 7.0) solution containing L-alanine and $\alpha-\mathrm{KG}$ as the substrate of GPT. Unless otherwise stated, the end concentration of $\mathrm{L}$-alanine was $100 \mathrm{mM}$ and of $\alpha-\mathrm{KG}$ was $1 \mathrm{mM}$. After the current decreased to its low initial or background level, $2 \mathrm{ml}$ of known enzyme activity solution was added to $4 \mathrm{ml}$ of the concentrated buffer solution, and the current-time curves were recorded. The initial slopes of the curves were determined as a function of the GPT activity. The initial slopes were plotted against the responses obtained for standard solutions determined by the Sigma GPT-assay kit, to determine a calibration graph. Commercial preparations of porcine heart GPT were dialysed against the appropriate buffer to remove ammonium sulfate prior to spiking into the serum samples.

The operational stability of the sensor in $100 \mu \mathrm{M}$ MSG during the first $10 \mathrm{~h}$ was determined each hour. The reproducibility of the sensor was assessed by successively checking the response to 10 and $100 \mu \mathrm{M}$ MSG solution. The strips were stored at $4{ }^{\circ} \mathrm{C}$ in PBS buffer or in a dry state. The storage stability was assessed by measuring $100 \mu \mathrm{M}$ MSG five times every 3-5 days over a 50-day period for electrodes stored in PBS. The storage stability of electrodes stored in a dry state was assessed fives times every month over a 6-month period.

\section{Results and discussion}

The biocatalyst scheme to measure GPT is illustrated in Fig. 1. The enzyme to be assayed, GPT, produces L-glutamate which is a substrate for the second enzyme, L-glutamate oxidase. The L-glutamate can be converted to $\mathrm{H}_{2} \mathrm{O}_{2}, \alpha-\mathrm{KG}$ and $\mathrm{NH}_{3}$ by L-GLOx. The $\mathrm{H}_{2} \mathrm{O}_{2}$ is an electroactive specie, which can easily be oxidized leading to an increase in current. The rate of current increase is proportional to the concentration

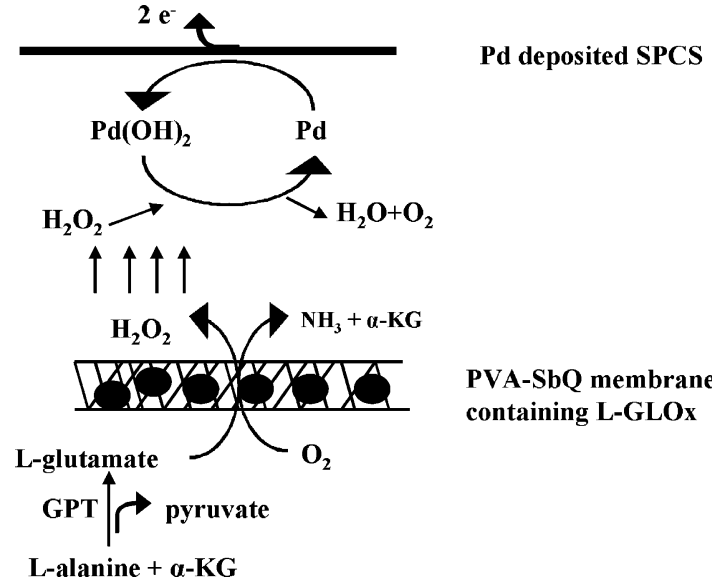

Fig. 1. Schematic diagram displaying the enzyme and electrode reactions involved in the GPT activity determination at an SPCS/ $\mathrm{Pd} / \mathrm{PVA}-\mathrm{SbQ} / \mathrm{L}-\mathrm{GLOx}$ electrode.

of GPT in the sample. In order to eliminate the electroactive species from reaction on the electrode, the electrocatalytic metal palladium was deposited on the prior to enzyme immobilization.

\subsection{Optimization of sensor response}

As shown in Fig. 2, the Pd-modified strip electrode exhibited an anodic response to hydrogen peroxide starting at $+0.2 \mathrm{~V}$, reaching its diffusion current limit at about $+0.4 \mathrm{~V}$. This result is in agreement with the findings of Chi and Dong [26] in similar experiments. When the L-GLOx film was present on the electrode surface, no obvious influence was observed on the electrocatalytic oxidation of hydrogen peroxide. However, a modest shift of the anodic peak in the positive direction was observed. In order to minimize the interference from electroactive species (e.g. ascorbic acid and uric acid), an operation potential of $+0.4 \mathrm{~V}$ was selected for the following tests.

The effect of $\mathrm{pH}$ on the response of the electrode (Fig. 3) was examined in the $\mathrm{pH}$ range from 5.0 to 9.5 using amperometry in stirred solution at $400 \mathrm{mV}$ versus $\mathrm{Ag} / \mathrm{AgCl}$. The maximum sensitivity was observed for buffer solutions adjusted to $\mathrm{pH}$ 7.0. Consequently this medium was selected for all remaining studies. This $\mathrm{pH}$ is close to the optimum $\mathrm{pH}$ observed for soluble L-GLOx, indicating that the PVA-SbQ membrane does not alter the optimum $\mathrm{pH}$ for catalytic behavior of L-GLOx. 


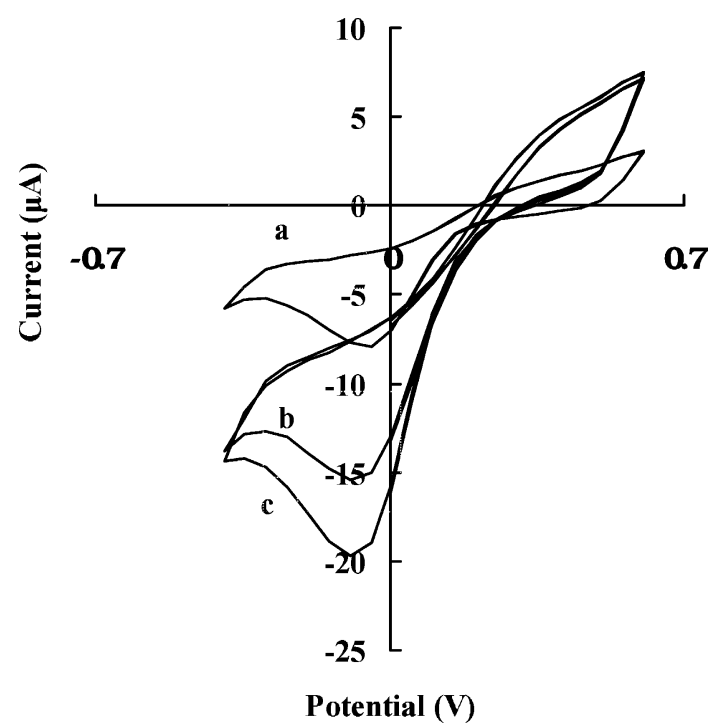

Fig. 2. Cylcic voltammograms of the palladium-modified screen-printing carbon strip. (a) SPCS/Pd in $100 \mathrm{mM}$ phosphate buffer solution; (b) SPCS/Pd in $100 \mathrm{mM}$ phosphate buffer solution containing $1 \mathrm{mM} \mathrm{H}_{2} \mathrm{O}_{2}$; (c) SPCS/Pd/PVA-SbQ/L-GLOx in $100 \mathrm{mM}$ phosphate buffer solution containing $1 \mathrm{mM} \mathrm{H}_{2} \mathrm{O}_{2}$.

The influence of the temperature on the sensitivity of the enzyme electrode was also studied. The sensitivity of the sensor increased with increasing in temperature from 15 to $80^{\circ} \mathrm{C}$ The maximum sensitivity was observed at $65^{\circ} \mathrm{C}$ (data not shown). Al-

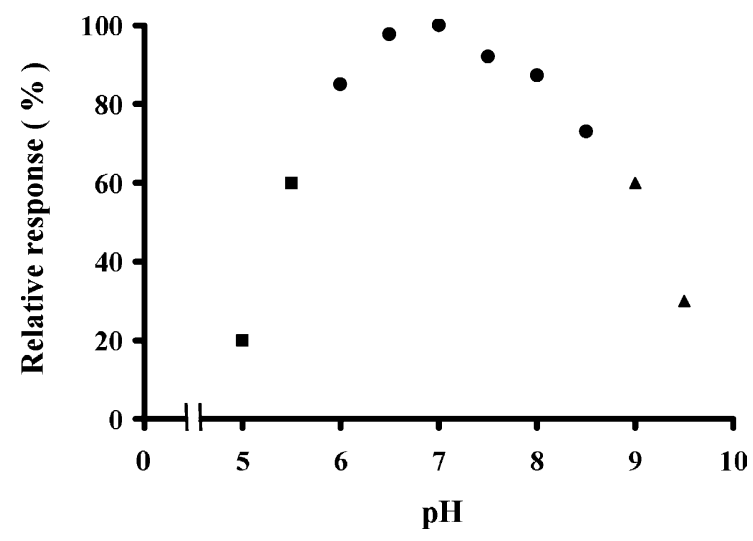

Fig. 3. Effect of $\mathrm{pH}$ on the response of the sensor. Measurements were carried out with $100 \mu \mathrm{M} \mathrm{L-glutamate}$ as substrate at $35^{\circ} \mathrm{C}$ in $100 \mathrm{mM}(\mathbf{)})$ phosphate buffer $(\boldsymbol{\square})$ citrate buffer $(\boldsymbol{\Lambda})$ carbonate buffer under stirring. The polarizing potential applied to the sensor was $0.4 \mathrm{~V}$ vs. $\mathrm{Ag} / \mathrm{AgCl}$. though the responsiveness of the electrode was enhanced at higher temperatures, the response of the sensor became unstable when the temperature reached $50{ }^{\circ} \mathrm{C}$. A temperature of $37^{\circ} \mathrm{C}$ was chosen for the following tests after consideration of normal body temperature and the stability of the electrode at this temperature.

\subsection{Influence of the photopolymer composition on sensor response and reproducibility}

The operational characteristics of the biosensor depend on the amount of PVA-SbQ and BSA deposited on the electrode as well as the glutaraldehyde exposure time. PVA-SbQ is a polyvinyl alcohol bearing a styrylpyridinium ( $\mathrm{SbQ}$ ) residue as its photosensitive group. The crosslinking of the polymer is performed using UV radiation to produce cyclodimerization of the styrylpyridinium groups [32-35]. Enzymes can be entraped in this polymer. However, the efficiency of the entrapment method can be improved by the use of intramolecular crosslinking reactions to bind enzyme molecules to each other, or by crosslinking via glutaraldehyde to a nonenzymic protein which is rich in L-lysine residues (such as bovine serum albumin).

The influence of glutaraldehyde on the activity of the electrode was studied by fixing the BSA and PVA-SbQ concentration at glutaraldehyde-exposure time of 0,4 and $12 \mathrm{~h}$. No apparent difference in the response of the electrode was found among these different exposure times. However, when the exposure time was less than $4 \mathrm{~h}$, the electrode became unstable during storage. This was due to failure of the crosslinkage to complete and to desorption of L-GLOx from the electrode into the buffer solution. When the exposure time was $12 \mathrm{~h}$, no significant difference in response was found after electrode fabrication. These results indicate that the L-GLOx can resist exposure to glutaraldehyde vapor for at least $12 \mathrm{~h}$. In order to achieve complete enzyme-to-enzyme and enzyme-to-BSA crosslinkage, an exposure time of $12 \mathrm{~h}$ was chosen for the following tests.

When the weight of PVA-SbQ solution used to construct the immobilized enzyme layer was lower than $25 \%$ of the total weight, lower responses and poor reproducibility were observed (Table 1). This was caused by the failure of the membrane to adhere 
Table 1

Effect of PVA-SbQ concentration on the response and reproducibility of the L-glutamate sensor $(n=5)$

\begin{tabular}{lcl}
\hline PVA-SbQ $(\%)^{\mathrm{a}}$ & Response $(\mathrm{nA})$ & R.S.D. $(\%)$ \\
\hline 15 & 670 & 47.32 \\
25 & 1147 & 14.68 \\
$25^{\mathrm{b}}$ & 998 & 7.43 \\
50 & 1130 & 20.11 \\
75 & $\mathrm{c}$ & $\mathrm{c}$ \\
\hline
\end{tabular}

${ }^{\text {a }}$ Percent of the total weight, the values correspond to the weight of the PVA-SbQ solution.

b $0.01 \%$ Fluorad FC-430 was added as surface active agent.

${ }^{\mathrm{c}}$ The immobilized enzyme membrane cracked into pieces.

the electrode during stirring. However, if higher than $50 \%$, the membrane cracked easily during stirring. The optimal amount of PVA-SbQ solution was decided as $25 \%$ of the total weight of the solution for constructing the immobilized enzyme layer.

A further study was carried out to investigate the effect of BSA concentrations of $0,2.5,5.0,10$ and $20 \%$ of the total weight. The responses of the sensor to $100 \mu \mathrm{M}$ MSG were $1386,1780,1299,572$ and $342 \mathrm{nA}$, respectively. BSA was used in conjunction with gluteraldehyde to create a 'protein membrane' where the BSA is believed to relieve steric interaction throughout the three-dimensional crosslinked matrix [36,37]. The increase of the BSA concentration results in the decrease of the biosensor response toward L-glutamate. This effect was determined by the diffusion limitation caused by the additional polymer layer. However, if the BSA concentration was lower than $2.5 \%$, the response was decreased. This was because the electrode surface failed to cover the electrode completely. The optimal concentration of BSA was thus decided as $2.5 \%$ of the total weight.

\subsection{Determination of $\mathrm{L}-$ glutamate concentration}

Fig. 4A shows the current-time response using the enzyme electrode under the optimized experimental conditions. A fast, sensitive response to change in the concentration of $1 \mu \mathrm{M}$ MSG was achieved. The enzyme electrode exhibited a linear calibration range in concentrations of MSG from $50 \mathrm{nM}$ to $100 \mu \mathrm{M}$ (Fig. 4B), with a slope of $12.18 \mathrm{nA} / \mu \mathrm{M}$ and a correla-

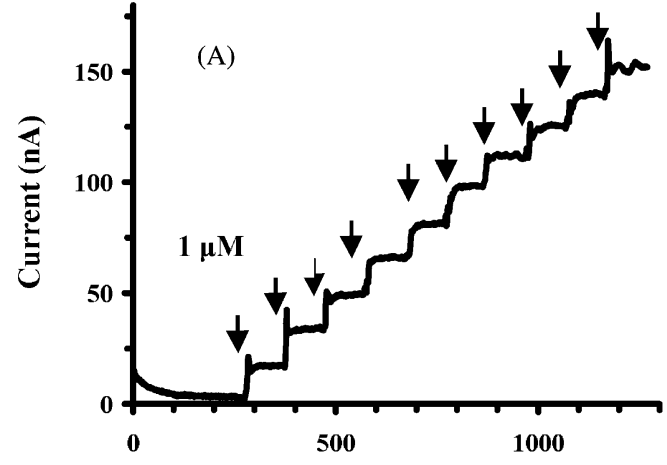

Time (seconds)

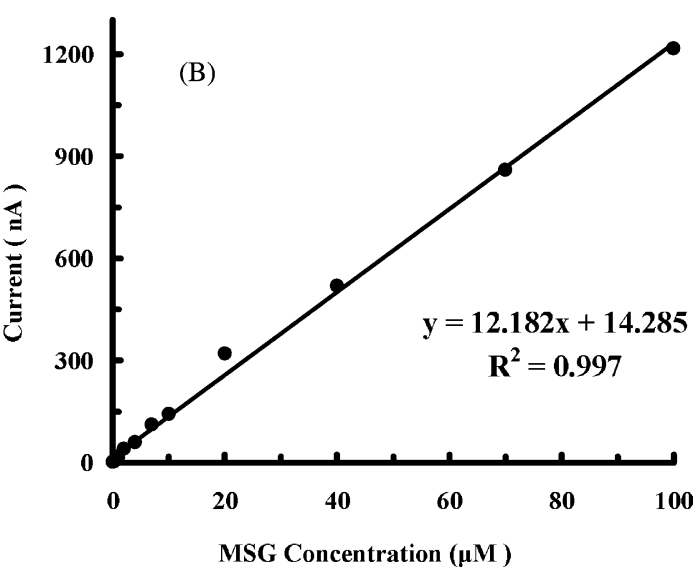

Fig. 4. (A) Amperometric response for successive additions of $1 \mu \mathrm{M}$ MSG for the L-GLOx sensor. The arrows indicated the time points of substrate addition. (B) Calibration graph of MSG on the L-GLOx sensor. Measurements were carried out at $35^{\circ} \mathrm{C}$ in $100 \mathrm{mM}$ sodium phosphate buffer $(\mathrm{pH}$ 7.0) under stirring. The polarizing potential applied to the sensor was $0.4 \mathrm{~V}$ vs. $\mathrm{Ag} / \mathrm{AgCl}$.

tion coefficient of $0.997(n=10)$. The detection limit of MSG was $50 \mathrm{nM}(S / N=3)$.

\subsection{Determination of GPT activity}

The $\alpha-K G$ is a co-substrate for the GPT catalysed transamination from $\mathrm{L}$-alanine to produce $\mathrm{L}$-glutamate and pyruvate. However, it inhibits the activities of the L-GLOx. An optimum concentration of $\alpha-K G$ was required to achieve a greater GPT sensitivity. In Fig. 5, the initial rates of the GPT response are plotted as a function of the $\alpha-K G$ concentration. The measurements were made at a concentration of $30 \mathrm{U} / \mathrm{l} \mathrm{GPT}$ by 


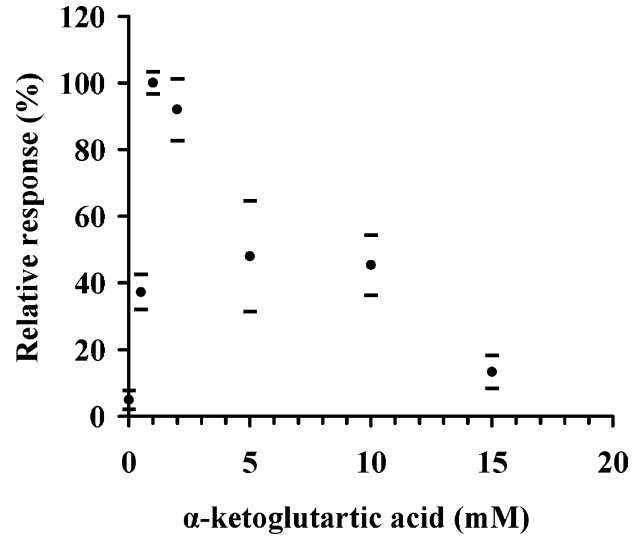

Fig. 5. Effect of $\alpha$-ketoglutarate concentration on reactivity of the sensor. The sensor was operated in $100 \mathrm{mM}$ sodium phosphate buffer ( $\mathrm{pH} 7.0$ ) containing $100 \mathrm{mM}$ L-alanine. The polarizing potential applied to the sensor was $0.4 \mathrm{~V}$ vs. $\mathrm{Ag} / \mathrm{AgCl}$.

adding $2 \mathrm{ml}$ of GPT standard solution into $4 \mathrm{ml}$ of the working solution in the reaction cell. The final concentration of $\alpha-\mathrm{KG}$ in the working solution was varied in the range from 0 to $15 \mathrm{mM}$ while the $\mathrm{L}$-alanine concentration was $100 \mathrm{mM}$. The maximum sensitivity was obtained when the $\alpha-K G$ concentration in the working buffer was $1 \mathrm{mM}$, and the response decreased rapidly when the $\alpha-\mathrm{KG}$ concentration exceeded $5 \mathrm{mM}$ (Fig. 5).

The effect of L-alanine concentration on the response of the sensor was tested by fixing the $\alpha-\mathrm{KG}$ concentration at $1 \mathrm{mM}$ and using L-alanine concentrations of 10, 20, 50 and $100 \mathrm{mM}$. The current increase rates were $0,4.5,14.4$ and $15.6 \mathrm{nA} / \mathrm{min}$, respectively. The response was increased as the L-alanine concentration increased. In the following tests, buffer containing $1 \mathrm{mM} \alpha-\mathrm{KG}$ and $100 \mathrm{mM}$-alanine was used as the working solution. Fig. 6A shows the current profile after the injection of the GPT standard solution. The current increased with extension of reaction time, indicating that the hydrogen peroxide released in the reaction was produced by the L-GLOx immobilized in the PVA-SbQ membrane. Since L-glutamate is a product of the transaminase reactions occurring in the buffer solution, the activity of GPT can be determined from the current increase in the L-glutamate sensor. The slopes of current increase with time obtained for various GPT standard solutions were plotted against the GPT activity determined by the Sigma GPT assay

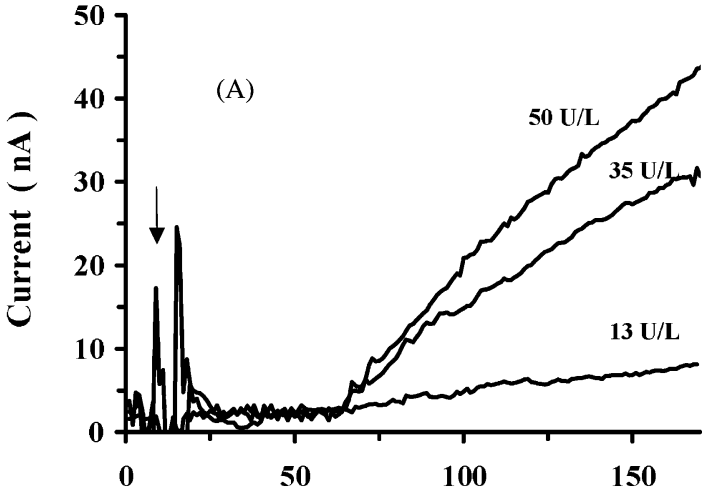

Time (seconds)

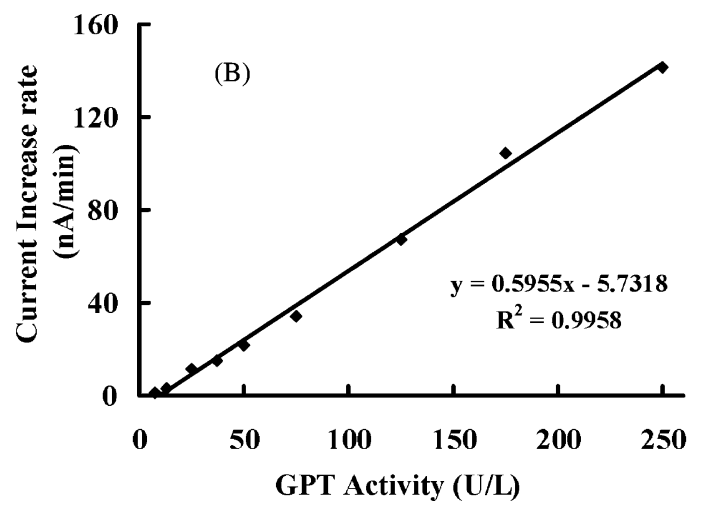

Fig. 6. (A) Response curves of the L-glutamate sensor. GPT solution with various concentrations was added to the working solution at the indicated times. (B) Calibration graph of GPT activity on the L-GLOx sensor. The concentration of L-alanine and $\alpha$-ketoglutarate in the working solution were 100 and $1 \mathrm{mM}$, respectively.

kit over the range of 8-250 U/1 $(y=0.5955 x-5.7318$, $\left.R^{2}=0.9958, n=9\right)$ to provide a calibration graph (Fig. 6B). According to Fig. 4, sensitivity of the enzyme electrode to MSG was $12.182 \mathrm{nA} / \mu \mathrm{M}$. Under the optimal condition, the adding $1 \mathrm{U} / \mathrm{l}$ GPT would produce glutamate with $1 \mu \mathrm{M} / \mathrm{min}$. According to Fig. 6B, however, the response of the GPT catalytic reaction was significantly smaller than the expected value. In a separate experiment, $1 \mathrm{mM} \alpha-\mathrm{KG}$ was added into the same working solution with $10 \mu \mathrm{M}$ MSG. The response of the sensor was reduced to $6 \mathrm{nA}$ (data not shown), i.e. a 20 -fold reduction from the response of the solution without $\alpha-K G$. The result suggests that $\alpha-\mathrm{KG}$ inhibits L-GLOx, causing a smaller response when measuring of GPT activity. 


\subsection{Stability and reproducibility of \\ the L-glutamate sensor}

Fig. 7 depicts the stability of the L-glutamate sensor in continuous operation mode at $35^{\circ} \mathrm{C}$. The measurement was performed by adding $100 \mu \mathrm{M}$ MSG five times per hour over a 10 -hour period. The response for the enzyme electrode in $100 \mu \mathrm{M}$ MSG gradually increased during the initial $4 \mathrm{~h}$ due to swelling of the membrane before it reached equilibrium. Similar results were also described by Zhang and Rechnitz [38]. The sensor response remained stable for the following $6 \mathrm{~h}$ even in a continuously stirred medium. This indicates a good operational stability of the enzymatic electrode and suggests this biosensor is suitable for multiple-use or continuous analysis.

The results on the sensor reproducibility are shown in Fig. 8. When an MSG concentration of $100 \mu \mathrm{M}$ was used for successive tests, the response of the electrode began to deteriorate after approximately 15 measurements (Fig. 8A). Therefore, an MSG concentration of $10 \mu \mathrm{M}$ was chosen for the subsequent experiments. A further experiment was performed involving continuous measurement of MSG every 2 min over a $200 \mathrm{~min}$ period. As shown in Fig. 8B, no significant difference was found in the response to $10 \mu \mathrm{M}$ MSG over a total of 100 tests. The relative standard deviation (R.S.D.) was found to be $2.6 \%$.

The stability of the sensor was affected by the storage conditions. When the sensors were stored in a dry state, no apparent change in the response was found during storage period of 5 months (Fig. 9A), while in

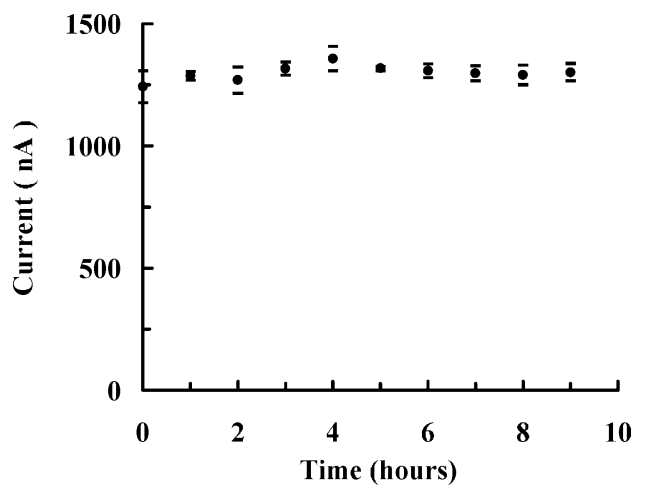

Fig. 7. Operational stability of the L-glutamate sensor at $35^{\circ} \mathrm{C}$. Each data obtained from five repeats to $100 \mu \mathrm{M}$ MSG. The polarizing potential applied to the sensor was $0.4 \mathrm{~V}$ vs. $\mathrm{Ag} / \mathrm{AgCl}$.
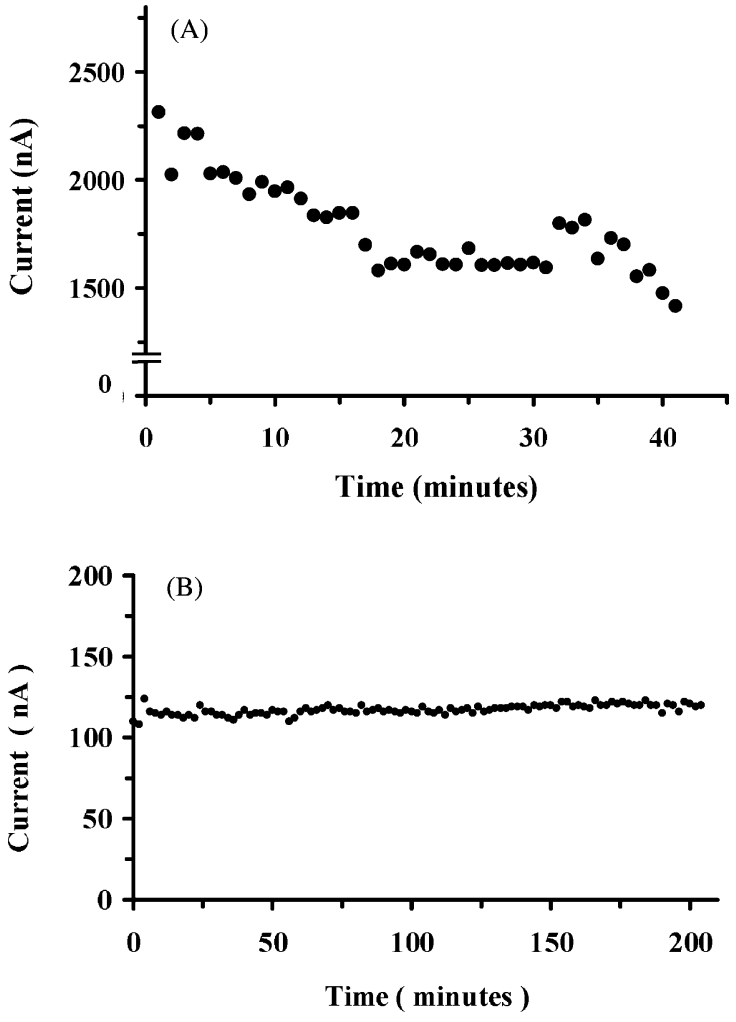

Fig. 8. Reproducibility of the L-glutamate sensor. The experiment was performed at $35^{\circ} \mathrm{C}$ by repeated measurement of (A) $100 \mu \mathrm{M}$ MSG and (B) $10 \mu \mathrm{M}$ MSG. The polarizing potential applied to the sensor was $0.4 \mathrm{~V}$ vs. $\mathrm{Ag} / \mathrm{AgCl}$.

the phosphate buffer ( $\mathrm{pH} 7.0)$ solution at $4{ }^{\circ} \mathrm{C}, 80 \%$ of the initial enzymatic activity was retained after a storage period of 30 days (Fig. 9B). This good stability can be attributed to the method of combining photo-crosslinking of PVA-SbQ and with a bifunctional agent (e.g. glutaraldehyde) to immobilize the enzyme, thereby preventing enzyme leakage $[39,40]$. This lifetime characteristic of the sensor can be explained by the inability of the enzymes to escape from the PVA-SbQ membrane because they are crosslinked in the BSA-glutaraldehyde matrix. The decreased activity of the enzymatic electrode can be attributed to mechanical damage to the enzymatic membrane during storage, as was ascertained by microscopic evidence of membrane peeling. Fig. 9B also illustrates the rapid decrease in response to electrodes not treated with glutaraldehyde vapor. An explanation for this phenomenon may be the loosing activity associated 

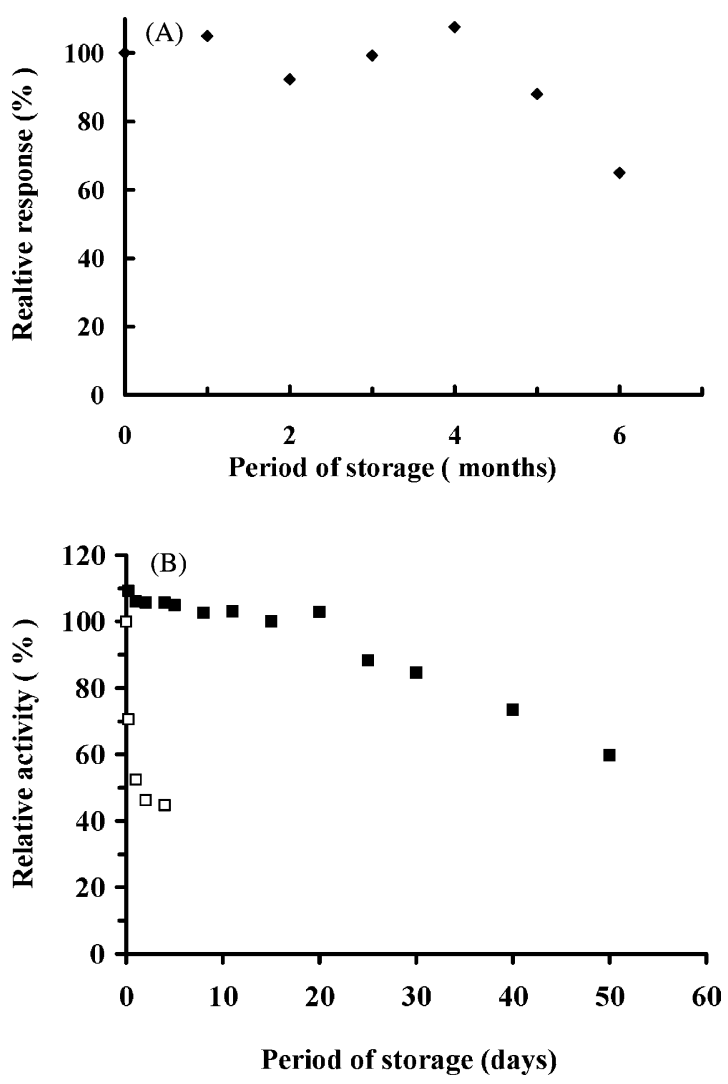

Fig. 9. Stability of the L-glutamate sensor during storage in (A) dry state and (B) phosphate buffer. ( $\square$ ) Without glutaraldehyde treatment. (ם) Exposed to glutaraldehyde vapor for $12 \mathrm{~h}$. Measurements were carried out with $100 \mu \mathrm{M}$ L-glutamate as substrate in $100 \mathrm{mM}$ sodium phosphate buffer $(\mathrm{pH} 7.0)$ at $35^{\circ} \mathrm{C}$. Each data is the mean value of three measurements.

with the enzyme-binding procedure, since some pore sizes may allow the escape of the enzyme. If the enzyme electrode is not treated with glutaraldehyde vapor, the enzyme-to-enzyme and enzyme-to-BSA covalent linkage cannot form. Untreated enzyme tends to leach out of the PVA-SbQ membrane because of its smaller molecule size leading to a reducing of enzyme-electrode activity.

\subsection{Interference from other electrochemically active substances}

Electrochemically active substances in serum such as ascorbic acid and uric acid, may cause severe interference on an electrochemical sensor system. In this study, the responses from electrochemically ac- tive species make an elevation of the baseline. They make no interference on a dynamical GPT determination when the dynamic data are taken after the steady state of an elevated baseline has been reached.

\section{Conclusion}

In this study, a Pd-modified SPCS L-glutamate sensor was fabricated to detect GPT activity. The electrode was immobilized with L-GLOx using the photo-crosslinkable polymer PVA-SbQ. This application of the photopolymer system for membrane formation was demonstrated to be suitable for automated production techniques and miniaturization of sensors using photolithography. The electrode demonstrated an MSG concentration detection limit of $0.05 \mu \mathrm{M}$. A linear relationship was found between MSG concentration and current in the range from 0.05 to $100 \mu \mathrm{M}$. This device has the potential for application in the food industry for the measurement of the flavor-enhancing agent MSG. The L-glutamate sensor can also be used for GPT-activity determination in a clinical testing. A linear relationship ( $y=$ $0.5955 x-5.7318, R^{2}=0.9958, n=9$ ) was found between the current increase rate and the various activities of GPT standard solution within the range of 8-250 U/l, which meets the clinical requirement for abnormal elevation of this enzyme in serum. The storage stability of the electrode in a dry state was 5 months. The reproducibility of the sensor was good with a coefficient of variation of $2.6 \%$ for 100 tests.

A portable GPT sensor for diagnostic and home-care purpose is highly expected. The mass production of the palladium-deposited screen-printed carbon electrode is possible. It is also possible to fabricate a portable measuring device with functions that fulfil the requirement of an amperometric measurement as used in this study. The combination of a portable measuring device with the sensor strip developed in this study will make a portable GPT biosensor possible.

\section{References}

[1] B. Rietz, G.G. Guilbault, Anal. Chim. Acta 77 (1975) 191.

[2] A. Karmen, F. Wroblewski, J.S. LaDue, J. Clin. Invest. 34 (1955) 126. 
[3] A. Karmen, J. Clin. Invest. 34 (1955) 131.

[4] S. Reitman, S. Frankel, Am. J. Clin. Pathol. 28 (1957) 56.

[5] B. Rietz, G.G. Guilbault, Clin. Chem. (Winston-Salen N.C.) 21 (1975) 1544.

[6] L.C. Clark, in: A.P.F. Turner, I. Karube, G.S. Wilson (Eds.), Biosensors, Fundamentals and Applications, Oxford Science Publications, New York, 1987, p. 11.

[7] International Federation of Clinical Chemistry, Clin. Chim. Acta 105 (1980) 147F.

[8] Y.N. He, H.Y. Chen, Anal. Chim. Acta 353 (1997) 319.

[9] C. Wrotnowski, Genet. Eng. News 2 (1998) 38.

[10] S.S. Rajinder, Biosens. Bioelectron. 9 (1994) 243.

[11] F. Scheller, Analyst 114 (1989) 653.

[12] E. Magner, Analyst 123 (1998) 1967.

[13] F. Mizutani, Y. Sato, T. Sawaguchi, S. Yabuki, S. Iijima, Sens. Actuators B 52 (1998) 23.

[14] U. Wollenberger, F.W. Scheller, A. Boehmer, M. Passarge, H.-G. Mueller, Biosensors 4 (1989) 381.

[15] D. Compagnone, G. Federici, R. Massouud, L. Santoro, M. Anichini, G. Palleschi, Clin. Chem. 38 (1992) 2306.

[16] J.M. Cooper, C.J. McNeil, J.A. Spoors, Anal. Chim. Acta 245 (1991) 57.

[17] R. Chuanmin, Y. Feng, L. Chenghong, D. Jiaqi, Anal. Chem. 70 (1998) 1721.

[18] I. Willner, A. Riklin, Anal. Chem. 66 (1994) 1535.

[19] B.K. Sohn, B.W. Cho, C.S. Kim, D.H. Kwon, Sens. Actuators B 41 (1997) 7.

[20] N. Jaffrezic-Renault, A. Senillou, C. Martelet, K. Wan, J.M. Chovelon, Sens. Actuators B 59 (1999) 154.

[21] R. Renneberg, K. Sonomoto, S. Katoh, A. Tanaka, Appl. Microbiol. Biotechnol. 28 (1988) 1.

[22] R. Rouillon, M. Tocabensand, J.L. Marty, Anal. Lett. 27 (1994) 2239
[23] I. Perdomo, C. Sundermeier, H. Hinkers, O.M. Morell, W. Seirt, M. Knoll, Biosens. Bioelectron. 14 (1999) 27.

[24] S.F. White, A.P.F. Turner, R.D. Schmid, U. Bilitewski, J. Bradley, Electroanalysis 6 (1994) 625.

[25] J.D. Newman, S.F. White, I.E. Tothill, A.P.F. Turner, Anal. Chem. 67 (1995) 4594.

[26] Q. Chi, S. Dong, Anal. Chim. Acta 278 (1993) 17.

[27] D.A. Johnston, M.F. Cardosi, D.H. Vaughan, Electroanalysis 7 (1995) 520.

[28] F. Mizutani, Y. Sato, Y. Hirata, T. Sawaguchi, S. Yabuki, Anal. Chim. Acta 364 (1998) 173.

[29] S. Dong, Q. Deng, C. Cheng, Anal. Chim. Acta 279 (1993) 235.

[30] L. Gorton, T. Svensson, J. Mol. Catal. 38 (1986) 49.

[31] S.F. White, A.P.F. Turner, R.D. Schmid, U. Bilitewski, J. Bradley, Electroanalysis 6 (1994) 625.

[32] J.D. Newman, S.F. White, I.E. Tothill, A.P.F. Turner, Anal. Chem. 67 (1995) 4594.

[33] K. Ichimura, S. Watanabe, J. Polym. Sci., Polym. Chem. Ed. 20 (1982) 1419.

[34] K. Ichimura, J. Polym. Sci., Polym. Chem. Ed. 22 (1984) 2817.

[35] C.Y. Chen, M. Gotoh, H. Makino, Y.C. Su, E. Tamiya, I. Karube, Anal. Chim. Acta 265 (1992) 5.

[36] N. Oyama, T. Ohsaka, M. Mizunuma, M. Kobayashi, Anal. Chem. 60 (1988) 2534.

[37] T. Abe, Y.Y. Lau, A.G. Ewing, J. Am. Chem. Soc. 113 (1991) 7421.

[38] X. Zhang, G.A. Rechnitz, Electroanalysis 6 (1994) 361.

[39] S. Dong, Y. Guo, Anal. Chem. 66 (1994) 3895.

[40] M.P.L. Gorton, R. Appelqvist, G. Marko-Varga, G. Joansson, Anal. Chim. Acta 246 (1991) 283. 